\title{
Research on the Balance and Coordination Scheme of CLSC under the Manufacturer's Competitive Environment
}

\author{
Hu Chengmu ${ }^{1, a}$ \\ ${ }^{1}$ Beijing Aerospace Hospital, Donggaodi Wanyuan Road No. 7, Fengtai District, \\ Beijing, China, 100076 \\ a932240446@qq.com
}

Keywords: Balance, coordination, CLSC, manufacturer's competitive environment

\begin{abstract}
CLSC this emerging field of science and becoming the focus of attention of business theory, the purpose of the closed-loop supply chain for effective management is to achieve coordinated development of "Economy and Environment", the management concept is conducive to enterprises and sustainable development of the whole society, enterprises, efficient closed-loop supply chain operations not only reduce production costs and enhance competitive advantage, but also indirectly enhance the corporate image; for society, can effectively control pollution, reduce energy and resource consumption, increase its efficiency. Aiming by two manufacturers and two closed-loop supply chain system a retailer to retailer responsible for the recycling of waste products as an example to study the closed-loop supply chain coordination strategy. Manufacturers and retailers have a coordinated strategy joint pricing trends, a coordinated strategy for manufacturers is a dominant decision.
\end{abstract}

\section{Introduction}

In recent years, environmental pollution and resource shortages in the rapid development of the global economy's performance is more prominent, and how to achieve economic, social and environmental development of coordination has become a worldwide issue. CLSC in theoretical paradigm of circular economy, the reverse recovery of waste products into the company's strategic business decisions under the system, so in the traditional supply chain management model based on the formation of a "resource - Production - Consumption - Renewable resources" the closed-loop chain, with feedback, a significant value-added features. However, since the height of recycled products in time, quantity and quality of uncertainty makes the study of closed-loop supply chain issues related to complex lot. In addition, competition and cooperation mechanisms within and outside the supply chain has a direct impact on the optimal business decisions, and in consideration of the supply chain members Research and channel competition competitive environment CLSC decisions related issues are becoming current management community hot spot [1].

Supply chain coordination is an important component of supply chain management research in the field of supply chain due to the selfish behavior of various actors and asymmetric information, each subject's behavior and decisions are often in conflict with the overall interests of the supply chain. According to consulting firm Deloitte study (Explore in 2005), it said that 91 percent of North American manufacturing companies included supply chain management key or key management activities, but only $2 \%$ of companies achieved good results, one of the most important the reason is the lack of effective coordination in supply chain management. Thus the establishment of effective coordination mechanisms to improve and optimize the overall performance of the supply chain is the core issue of supply chain management.

Currently, there are a number of domestic and international research coordination in contract supply chain, but due to a late start, has not yet formed a complete theoretical system. Savaskan applications such as game theory duopoly reverse supply chain optimal choice questions one by the manufacturers, retailers and third party is responsible for three different channel structure of recycling. On the results of the decentralized decision-making compared with centralized decision-making, it explains CLSC potential inefficiencies. Savaskan others, based on the study 
Savaskan distribution channels by two reverse supply chain a manufacturer and two retailers, analyzes the manufacturers directly responsible for the recovery and recycling efficiency by the retailer in both cases, with the Game theory analysis framework, the study of supply chain members independently in the forward and reverse logistics decision profit impact of closed-loop supply chain. Gu Qiaolun studied the optimal pricing strategy and its efficiency reverse supply chain system of recycling of waste products, although the study of the recycling of waste products as a retailer price decision variables, but did not consider competition issues retailers there is no coordination problems involving closed-loop supply chain.Wang Yuyan used the supply chain coordination method commonly used in closed-loop Stackelberg game of supply chain based on a single manufacturer and a single retailer constitution were studied, analyzed CLSC pricing strategy compared equilibrium and non-cooperative game cooperative game The equilibrium solution further gives the corresponding pricing strategy and coordination mechanism. Previous studies mostly concentrated in the case of duopoly, few studies are many horizontal competition, and in the case of many-to-many and very little research. In this paper, the secondary loop supply chain system consists of two manufacturers and one retailer, the retailer is responsible for balance and coordination strategies for recycling old product research and Closed Loop Supply Chain [2].

\section{The Research of Supply Chain Coordination}

Supply chain coordination is an important means of achieving integration between the supply chain and supply chain node enterprise collaboration and coordination mechanisms with respect to the reverse supply chain contract problems, Cachon Nash equilibrium of the game from the perspective of any individual obtained if the supply chain members are reluctant to re- deviate from one equilibrium point, that is to achieve a coordinated supply chain. Cachon and Lariviere further analysis of the revenue-sharing contract advantages and disadvantages, and several other categories of supply chain coordination contract were compared. Yan Nina, Huang Yuan, Bing studied loop supply chain channel coordination problems with product recovery is established manufacturers and sellers while engaged Stackelberg game model CLSC recycling of old products, and gives a balanced policy and closed-loop supply chain channel coordination strategy. Shi Chengdong for loop supply chain risk aversion characteristics has proved that coordination volume discount contract and revenue sharing contract balanced closed-loop supply chain. Xiaoying and other package based on the following new products and remanufactured products Differences pricing and coordination of closed-loop supply chain.

Further, Walther et al. Consider a law driven by the waste materials recycling networks, decentralized decision-making in the negotiations through the establishment of some mechanism to achieve a coordinated supply chain, and will coordinate benefits with other coordination mechanisms of state conduct contrast, illustrates the effectiveness of the coordination mechanism. Wang Wenbin, Da Qingli assumed that manufacturers and governments have developed an incentive mechanism for recyclers, and then were compared the effect of two different mechanisms of reward and punishment on the amount of recycling, the conclusions show that the government's incentive mechanism to achieve decentralization CLSC coordination. In consumer products under the new and remanufactured product preferences indifference analyzed the pricing policy and coordination of closed-loop supply chain, market size research results in new products and re-manufacturing output decisions will produce more products big impact: remanufactured products to meet the needs of smaller markets, but with the increase in market demand, the new products and remanufactured products mixed supply strategy to make the closed-loop supply chain decisions optimal. Chen and Bell studied the coordination of a single closed-loop supply chain consisting of manufacturers and retailers, using repurchase contracts to achieve a diversified closed-loop supply chain, coordinated operation, so that retailers and manufacturers to achieve a "win-win" state [3]. 


\section{The Related Research of Closed-loop Supply Chain}

Many scholars from different angles on closed-loop supply chain were studied. First, some scholars pricing and coordination of different network structures closed-loop supply chain. Savaskan put forward three recovery modes in a monopoly manufacturer and a retailer under: Manufacturer recycling, recovery and third-party retailers, recycling, to compare the three modes found in the highest recovery efficiency at the retailer recovery; Savaskan and so further discussed in the market structure of a single manufacturer and retailer of two competing manufacturers and retailers recycle recycling decentralized decision-making and centralized decision-maker in pricing strategies and coordination mechanisms; Wang Wenbin research incentive mechanism under closed-loop supply decision-making and coordination chain; Lauren and other studies of the original product and joint pricing and production technology selection remanufactured products give manufacturers the optimal remanufacturing decisions, and the results are extended to the competitive environment; Sun Hao and other studies remanufacturing loop supply chain pricing strategy and coordination mechanism based on two cycles of product differentiation.

Second, some scholars have studied the presence of competing manufacturers CLSC. Ferguson and other considerations pricing strategy remanufacturers competitive environment, get a cost conditions to meet the conditions under monopoly or competition in the recycling and remanufacturing economically feasible; Atasu comprehensive consideration of the existence of the green market, the manufacturer manufacturers pricing competition and product life cycle under the circumstances, the results show that when there is competition, remanufacturing is a good competition means manufacturers, manufacturers can improve the market by re-manufactured products and the difference between the original product pricing share; Chen Shulin and other improved multi-vendor competition remanufacturing loop supply chain production planning, production planning for the development of enterprises to provide a solution; Han floret study CLSC recovered under competitive market structure manufacturers shared retailer channel decision-making process; Cao Jun was studied in two phase CLSC new parts manufacturer and re-manufacturer's price and quality levels to compete under dynamic game model [4].

Finally, some scholars have studied the life cycle of the product based on closed-loop supply chain. Ferrer, respectively, consider the two monopolistic competition and Doppler competitive environment, multiple and unlimited product life cycle loop supply chain under the pricing strategy, results showed that if we made a big profit, then manufacturers in product the first life cycle to reduce the sales price so that more of remanufactured products in future periods; if the competition is fierce, manufacturers completely remanufactured sell at low prices to gain competitive advantage. Ferrer and so further study of two cycles of monopolistic competition and remanufactured products and the original product under significantly different circumstances and multi-cycle pricing strategy.

\section{The Problem Description and Basic Assumptions}

CLSC by a duopoly constituted manufacturer and a retailer, manufacturers and retailers are risk neutral and independent decision-makers, that is without considering the cost of risk arising both risk appetite; the manufacturers and retail Suppliers for recycling and remanufacturing capability unrestricted, individual goals are to maximize profits. This section considers the complete information in a single cycle loop supply chain game.

Assuming two manufacturers in the duopoly market have the same competitiveness and performance of Cournot competition between two manufacturers. We use the following linear demand function:

$$
Q_{i}=\phi-P_{\mathrm{i}}+\theta P_{j}, i \neq j, i, j=1,2
$$

where $Q_{i}$ market demand for manufacturers, $P_{\mathrm{i}}$ product the retail price, the prospective market 
size, $\quad \theta$ is the substitution effect between product manufacturers, and $0<\theta<1$.

Assuming the same quality of new products and recycled products, consumer acceptance of recycled products and new products are the same $\mathrm{Cm}$. Two manufacturers of full use of the unit cost of raw materials are $\mathrm{Cm}$, the use of recycled products remanufactured unit costs are $\mathrm{Cr} . \triangle=$ $\mathrm{Cm}$ - $\mathrm{Cr}$ provided that the use of recycled products remanufacturing costs savings. Manufacturers in the same repurchase price b recovering waste products from retailers; of waste products are fully remanufactured, remanufactured products and no differences in the nature of new products.

The amount of recovered waste products $G(r)$ for retailers recycle price nonlinear increasing function of $r$. Set $G(r)=a r k$, $a>0$, a conversion constant; $k>1$, for consumers to recycle price sensitivity coefficients. Marginal cost recovery retailers to c.

Background of extended producer responsibility system, in most cases the manufacturer of closed-loop supply chain leading enterprises, accounting for decision superiority. So study led by manufacturers, retailers followers Stackelberg Game.

$\prod_{M}$ represents the manufacturer's profit, $\prod_{R}$ represents the retailer's profit, $\prod_{i}$ where i represents the total profits of the product supply chain, namely the profits of manufacturers and retailers i and i recycle products and the resulting profits [5] .

\section{The Balance and Coordination of Loop Supply Chain}

\section{Decentralized decision-making mode.}

Between manufacturers and retailers are independent decision maker for the leader, the manufacturer first determine their wholesale price and the repurchase price Wi bi, after the retailer accordingly determine their own retail prices for consumers and $\mathrm{Pi}$ recycling prices ri. Manufacturers and retailers profit functions are as follows:

$$
\begin{aligned}
& \prod_{M i}=\left(\phi-P_{\mathrm{i}}+\theta P_{j}\right)\left(W_{i}-C m\right)+\left(\Delta-b_{i}\right) G\left(r_{i}\right) \\
& \prod_{R}=\sum_{i=1, i \neq j}^{2}\left(P_{i}-W_{i}\right)\left(\phi-P_{\mathrm{i}}+\theta P_{j}\right)+\left(b_{i}-r_{i}-C_{2}\right) G\left(r_{i}\right)
\end{aligned}
$$

The two manufacturers have a coordinated strategy. When manufacturers and retailers a coordinated joint pricing policy, the closed-loop supply chain is equivalent to only one decision maker, the decision-makers to maximize profits loop supply chain system as the goal. Namely manufacturers and retailers through joint decision-making price the whole supply chain and maximize profits. When manufacturers have a coordinated strategy, supply chain profit function is

$$
\begin{aligned}
& \prod_{1}=\left(P_{1}-C_{m}\right)\left(\phi-P_{1}+\theta P_{2}\right)+\left(\Delta-r_{1}-C\right) G\left(r_{1}\right) \\
& \prod_{2}=\left(P_{2}-C_{m}\right)\left(\phi-P_{2}+\theta P_{2}\right)+\left(\Delta-r_{2}-C\right) G\left(r_{2}\right)
\end{aligned}
$$

\section{Summary}

A coordinated strategy is a balanced state, compared with independent decision-making, increase profits. The equivalent of a coordinated strategy for manufacturers and retailers to raise consumer utility by lowering retail prices. At the same time, raise the cost of recycling the waste products remanufacturing get part of the profits returned to the consumer, not only between the two reached a win-win situation, but consumers also benefit from real manufacturers, retailers and consumers win-win situation .

\section{References}

[1] Yijun Chen: Sci-Tech Information Development \& Economy, Vol. 10 (2004) No 17, p.45-46

[2] Tong Han: System Engineering Theory and Practice, Vol. 12 (2010) No 28, p.74-76

[3] Lihua Xu: Marketing Science, Vol. 1 (2006) No 33, p.22-26

[4] Savaskan, R .C., Van Wassenhove :Management Science,Vol. 3 (2006) No24, p.1-14

[5] Savaskan, R .C., Bhattacharya, S.: Management Science, Vol. 9 (2004) No 33, p.11-14 